Opinion

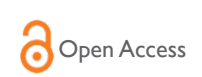

CrossMark

\title{
A reflection on request: an opinion
}

\section{Opinion}

It is a source of great joy and excitement to have the opportunity to write a piece of reflection in one of the most important journals in the world in gynecology and obstetrics, with the tranquility based on several decades of practice in public and private medicine.

I believe humbly that having chosen as a specialty obstetrics and gynecology in general, and diagnostic ultrasound and maternal fetal medicine in particular, is the best choice in my professional life.

My eyes and my mind have witnessed changes so spectacular, transcendent and dreamed by my teachers and mentors. "Faith creates reality and reality often surpasses fantasy", a slogan used to convince many colleagues to hold the FIGO 2003 congress in Chile. A success without any doubt. Let's not stop dreaming and create a better world.

Not remembering the recent past in which the obstetrician only contacted a measuring tape to quantify gestational age through uterine height and a Pinar stethoscope to listen to the fetal heartbeat and deduce fetal well-being, the art of palpate the fetal presentation and diagnosis possible pathologies, "An artist" tanned by time, but with an inaccuracy sometimes unwanted.

The same in general gynecology and its subspecialties, in which the experience and wisdom of our guides allowed a privileged attention of our self-sacrificing women.

The most beautiful of our specialty is having been an instrument to bring so many babies to the world, to see them grow and many of them better than us.

We have taught these paradigms to several generations, "The disciple often overcomes the teacher" so many times, being a source of pride and spiritual joy.

We have also aged with our patients and assisted them in all the most important stages of their lives, there is no other specialty, even if they look for it with a candle.

Undoubtedly, advances especially in ultrasound and molecular biology have been fundamental pillars in the development of embryology, physiology, anatomy of the mother-child binomial, not to mention the extraordinary advances of reproductive medicine, oncology, chemotherapy, robotic surgery to mention just a few advances.
Volume 9 Issue I - 2018

\author{
Eghon Guzman \\ Hospital Dr. Sotero del Rio, Integramedica Bupa, Chile \\ Correspondence: Eghon Guzman, Hospital Dr. Sotero del Rio, \\ Integramedica Bupa, Santiago, Chile, \\ Email eguzmanb@gmail.com \\ Received: January 31, 2018| Published: February 15, 2018
}

Exponential knowledge, research on the frontier of current medicine have been the cause of an immeasurable wisdom. However, we must not forget that a woman still dies every 90 seconds for the mere fact of getting pregnant, and that one dies every 120 seconds due to uterine cervical cancer and worse, a child dies every 6 seconds due to hunger. Inequality and injusticestrike our conscience and push us to continue dreaming for a better world.

As my interlocutor said that a single candle illuminates a complete piece, the will of many will change the course towards the future.

I must say as a corollary that nothing is original; all the maxims are said and better than this server, but the main task are to put them into practice to be consistent with our beautiful profession.

\section{Acknowledgements}

None.

\section{Conflicts of interest}

None. 